\title{
INJECTABLE BMP-2 DELIVERY SYSTEM BASED ON COLLAGEN- DERIVED MICROSPHERES AND ALGINATE INDUCED BONE FORMATION IN A TIME-AND DOSE-DEPENDENT MANNER
}

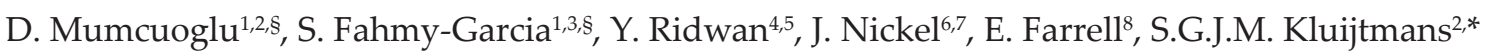 \\ and G.J.V.M van Osch ${ }^{1,9}$
}

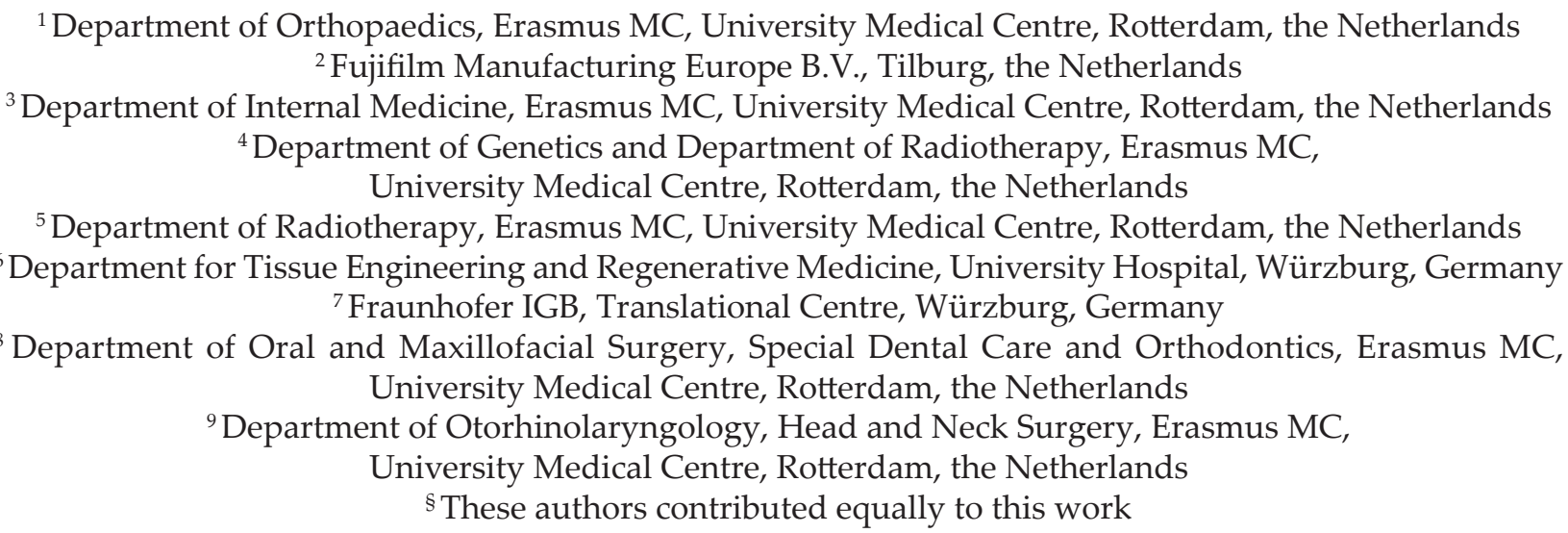

\begin{abstract}
The aim of the current study was to reduce the clinically used supra-physiological dose of bone morphogenetic protein-2 (BMP-2) (usually $1.5 \mathrm{mg} / \mathrm{mL}$ ), which carries the risk of adverse events, by using a more effective release system. A slow release system, based on an injectable hydrogel composed of BMP-2-loaded recombinant collagen-based microspheres and alginate, was previously developed. Time- and dose-dependent subcutaneous ectopic bone formation within this system and bone regeneration capacity in a calvarial defect model were investigated. BMP-2 doses of $10 \mu \mathrm{g}, 3 \mu \mathrm{g}$ and $1 \mu \mathrm{g}$ per implant $(50 \mu \mathrm{g} / \mathrm{mL}, 15 \mu \mathrm{g} / \mathrm{mL}$ and $5 \mu \mathrm{g} / \mathrm{mL}$, respectively) successfully induced ectopic bone formation subcutaneously in rats in a time- and dose-dependent manner, as shown by micro-computed tomography $(\mu \mathrm{CT})$ and histology. In addition, the spatio-temporal control of BMP-2 retention was shown for 4 weeks in vivo by imaging of fluorescentlylabelled BMP-2. In the subcritical calvarial defect model, $\mu$ CT revealed a higher bone volume for the $2 \mu \mathrm{g}$ of BMP-2 per implant condition $(50 \mu \mathrm{g} / \mathrm{mL})$ as compared to the lower dose used $(0.2 \mu \mathrm{g}$ per implant, $5 \mu \mathrm{g} /$ $\mathrm{mL}$ ). Complete defect bridging was obtained with $50 \mu \mathrm{g} / \mathrm{mL}$ BMP-2 after 8 weeks. The BMP-2 concentration of $5 \mu \mathrm{g} / \mathrm{mL}$ was not sufficient to heal a calvarial defect faster than the empty defect or biomaterial control without BMP-2. Overall, this injectable BMP-2 delivery system showed promising results with $50 \mu \mathrm{g} / \mathrm{mL}$ BMP-2 in both the ectopic and calvarial rat defect models, underling the potential of this composite hydrogel for bone regeneration therapies.
\end{abstract}

Keywords: Bone morphogenetic protein-2, slow release, injectable delivery system, ectopic bone formation model, calvarial bone defect model.

*Address for correspondence: Sebastiaan Kluijtmans, FUJIFILM Manufacturing Europe B.V., Oudenstaart 1, 5047 TK Tilburg, the Netherlands.

Telephone: + $31135791172 \quad$ Email: bas.kluijtmans@fujifilm.com

Copyright policy: This article is distributed in accordance with Creative Commons Attribution Licence (http://creativecommons.org/licenses/by-sa/4.0/).

\section{Introduction}

Autologous bone is widely used in bone grafting surgery. However, its limited availability and the discomfort related to the harvesting procedure have diverted the field to seek for alternative methods involving biomaterials (Polo-Corrales et al., 2014). Bone morphogenetic proteins (BMP-2 and BMP-7), 
being successful in inducing bone formation, are already translated to clinics (McKay et al., 2007). BMP-2 absorbed on a collagen sponge is approved by the United States Food and Drug Administration for spinal fusion, tibial non-unions and oral-maxillofacial reconstructions (Burkus et al., 2002; Rengachary, 2002). However, adverse events observed in clinics have limited the use of BMP-2, especially for off-label applications (Epstein, 2013; Poon et al., 2016; Shields et al., 2006; Woo, 2012). These adverse events, mainly inflammation (Zara et al., 2011) and swelling (Perri et al., 2007), are associated with the supra-physiological dose of BMP-2 loaded onto the collagen sponge (James et al., 2016), in combination with the strong burst release. Half of the loaded BMP-2 is released from the collagen sponge in the first $2 \mathrm{~d}$ in vivo ( $\mathrm{Li}$ and Wozney, 2001). Possibly, these adverse events can be mitigated by using an appropriate release system comprising a lower BMP-2 dose (Agrawal and Sinha, 2016; Mumcuoglu et al., 2017). Such a system might broaden the potential use of BMP-2 in orthopaedic and maxillofacial surgery applications.

The dose or concentration of BMP-2 is very important for bone formation (Bessa et al., 2008; Choi et al., 2016; Yamaji et al., 2007). Since no naturally bone-forming cells are present within the intradermal environment, subcutaneous ectopic bone can only be formed by injecting bone-forming cells or an osteoinductive protein, such as BMP-2, that can recruit progenitor cells (Scott et al., 2012). The concentration or dose of BMP-2 required to induce ectopic bone formation depends on the type of carrier material used. For example, using $5 \mu \mathrm{g}$ of BMP-2, $32 \%$ bone formation is achieved using a $9 \mathrm{~mm}^{3} \beta$-tricalcium phosphate scaffold, whereas hydroxyapatite, with the same amount of BMP-2, only yields $3 \%$ bone formation in a rat ectopic model (Tazaki et al., 2009). $5 \mu \mathrm{g}$ of rhBMP-2, implanted with a $6 \mathrm{~mm}$ in diameter collagen sponge, are required to induce a small intramuscular bone formation in mice, with a maximum volume of $5 \mathrm{~mm}^{3}$ (Kim et al., 2011). $10 \mathrm{mg}$ of silk fibroin particles, loaded with $5 \mu \mathrm{g}$ of BMP-2, induce the formation of a small volume $\left(2 \mathrm{~mm}^{3}\right.$ ) of ectopic bone after 4 weeks in rats (Bessa et al., 2010). A low dose of BMP-2 (less than $1 \mu \mathrm{g}$ ), delivered on a collagen sponge or with brushite calcium-phosphate particles, does not form any bone in the palatal submucosa of rats (Martinez-Sanz et al., 2012), confirming the presence of a threshold dose. This threshold depends on the type of material and application site and is associated with the release kinetics/degradation time of the material and subsequent cellular infiltration rate (Bessa et al., 2008).

An in situ gelling sustained-BMP-2-release system, which induces ectopic bone formation, is available (Fahmy-Garcia et al., 2016). This hydrogel system is based on BMP-2-loaded microspheres, composed of a recombinant peptide based on the sequence of collagen I (RCP), embedded in a high guluronate-type-alginate. The use of RCP allows for a reproducible production, without risks of disease transmission, which can be associated to purified collagen materials. More importantly, RCP has excellent cell attachment properties (Parvizi et al., 2016) and a specific affinity to bind BMP-2 (Mumcuoglu et al., 2018), which makes it appealing as a controlled release system. The main advantages of the developed system are its thixotropic behaviour, resulting in easy handling and injectability, good BMP-2 release profile and good performance in vivo in terms of cellular infiltration, degradation and bone formation (Fahmy-Garcia et al., manuscript under revision). The aim of the current study was to investigate time- and dose-dependent bone formation using this BMP-2-releasing hydrogel in an ectopic bone formation model and, in addition, to test the bone regeneration capacity of two selected doses of BMP-2 in an orthotopic model. Formulations containing 4 different doses of BMP-2 (10 $\mu \mathrm{g}, 3 \mu \mathrm{g}$, $1 \mu \mathrm{g}$ and $0.3 \mu \mathrm{g}$ per implant; $50 \mu \mathrm{g} / \mathrm{mL}, 15 \mu \mathrm{g} / \mathrm{mL}$, $5 \mu \mathrm{g} / \mathrm{mL}$ and $1.5 \mu \mathrm{g} / \mathrm{mL}$, respectively) and an empty control were injected subcutaneously into the dorsum of immune-competent rats. Ectopic bone formation was followed over a time course of 10 weeks by micro-computed tomography $(\mu \mathrm{CT})$, with histology at the endpoint of 10 weeks. To study the spatiotemporal release of BMP-2 in vivo, formulations containing 3 different doses of fluorescently-labelled BMP-2 were injected subcutaneously into rats and monitored over a time course of 10 weeks by in vivo fluorescence imaging. Finally, two doses of BMP-2 $(50 \mu \mathrm{g} / \mathrm{mL}$ and $5 \mu \mathrm{g} / \mathrm{mL})$ were further investigated in a calvarial defect model. For this purpose, $40 \mu \mathrm{L}$ of the composite hydrogel formulation, containing $2 \mu \mathrm{g}$ and $0.2 \mu \mathrm{g}$ of BMP-2, were injected in $5 \mathrm{~mm}$ subcritical calvarial defects in immune competent rats and bone formation was studied by $\mu \mathrm{CT}$ longitudinal imaging for 10 weeks.

\section{Materials and Methods}

\section{Materials}

RCP is a product of Fujifilm, which is commercially available as Cellnest ${ }^{\mathrm{TM}}$. RCP is produced by the genetically modified yeast Pichia pastoris in a fermentation process previously described (De Boer et al., 2012; Parvizi et al., 2016; Tuin et al., 2010). RCP is a 571 amino acids protein, having an isoelectric point (pI) of 10.02 and a molecular weight of $51.2 \mathrm{kDa}$.

The recombinant human bone morphogenetic protein-2 (rhBMP-2, amino acids 283 to 396 plus an N-terminal Met-Ala) was expressed in Escherichia coli, isolated from inclusion bodies, renatured and purified, as previously described (Kirsch et al., 2000). Lyophilised BMP-2 was dissolved in distilled water and the concentration was determined by UV/ Vis spectrophotometry. Freshly dissolved BMP-2 was used for the experiments. For the fluorescence measurements, rhBMP-2 was fluorescently-labelled using DyLight ${ }^{\mathrm{TM}} 800$ (ThermoFisher Scientific). For the labelling, dissolved BMP-2 solution was adjusted 
to $\mathrm{pH} 4.5$ by addition of a $2 \mathrm{M}$ sodium acetate ( $\mathrm{pH} 4.5)$ solution. Subsequently, DyLight ${ }^{\mathrm{TM}} 800$ NHS Ester, dissolved in dimethyl sulphoxide (DMSO), was added in a 5 fold molar excess and the mixture was incubated for $4 \mathrm{~h}$ at $4{ }^{\circ} \mathrm{C}$ while shaking. After incubation, the protein was separated from noncoupled dye by anionic exchange chromatography using a HiTrap ${ }^{\circledR}$ SP HP column (GE Healthcare). Since the protein could not be eluted even at $2 \mathrm{M}$ sodium chloride salt concentration, it was recovered using an aqueous $6 \mathrm{M}$ guanidinium hydrochloride solution. Subsequently, the protein was dialysed to $1 \mathrm{mM}$ hydrochloric acid and finally to distilled water.

PRONOVA ${ }^{\mathrm{TM}}$ SLG20 (sterile alginate, where over $60 \%$ of the monomer units are guluronate) was ordered from NovaMatrix (Sandvika, Norway). The properties of the SLG20 alginate are assessed by the producer: viscosity $(\mathrm{mPa} \times \mathrm{s})$ : 20-99; approximate molecular weight (kDa): 75-150; guluronate/ mannuronate $(\mathrm{G} / \mathrm{M})$ ratio: $\geq 1.5$; endotoxins $(\mathrm{EU} / \mathrm{g})$ : $\leq 100$; total viable count [colony forming unit (cfu)/g]: sterile (www.novamatrix.biz). Hexamethylene diisocyanate (HMDIC), corn oil, sodium chloride, calcium carbonate $\left(\mathrm{CaCO}_{3}\right)$ and glucono delta lactone (GDL) were purchased from Sigma-Aldrich. Ethanol, acetone and hydrochloric acid were purchased from Millipore. The ELISA development kit and reagents for BMP-2 quantification were ordered from Peprotech (Rocky Hill, NJ, USA). Dulbecco's modified Eagle's medium (DMEM), foetal bovine serum (FBS) and penicillin-streptomycin $(\mathrm{P} / \mathrm{S})$ were ordered from ThermoFisher Scientific.

\section{RCP microsphere preparation}

RCP-calcium carbonate composite microspheres were produced by emulsification, as described previously (Mumcuoglu et al., 2018). Briefly, a $20 \%$ aqueous RCP solution was prepared and mixed with $\mathrm{CaCO}_{3}$ fine powder (with a size of $<1 \mu \mathrm{m}$ ) in a $1: 1(\mathrm{w} / \mathrm{w})$ ratio. This suspension was emulsified in corn oil at $50{ }^{\circ} \mathrm{C}$, while stirring the emulsion at $800 \mathrm{rpm}$ for $20 \mathrm{~min}$. After cooling down the emulsion, the emulsified microspheres were washed three times with acetone. After overnight drying at $60^{\circ} \mathrm{C}$, microspheres were sieved to 50-72 $\mu \mathrm{m}$ size using sieves from Retsch $\mathrm{GmbH}$ (Haan, Germany). Subsequently, particles were crosslinked by hexamethylene diisocyanate (HMDIC) by mixing and stirring of $1 \mathrm{~g}$ of spheres and $1 \mathrm{~mL}$ of HMDIC in $100 \mathrm{~mL}$ ethanol for $1 \mathrm{~d}$. Non-reacted crosslinker was removed by washing several times with ethanol. $\mathrm{CaCO}_{3}$ was left in the particles since $\mathrm{Ca}^{2+}$ ions are used to crosslink alginate in the final hydrogel formulation. Particles were then $\gamma$-sterilised at $25 \mathrm{kG}$ (Synergy Health, Etten Leur, the Netherlands). The release of BMP-2 from RCP microspheres is described by Mumcuoglu et al. (2018).

\section{Preparation of the RCP microsphere-alginate hydrogel formulations}

SLG-20 alginate was dissolved in $0.9 \%$ sterile sodium chloride to create a $2 \% \mathrm{w} / \mathrm{v}$ solution. $68 \mathrm{mg}$ of sterile microspheres were incubated with $170 \mu \mathrm{L}$ of BMP-2containing solution at $4{ }^{\circ} \mathrm{C}$ overnight. Initial BMP-2 concentrations used were $379.4 \mu \mathrm{g} / \mathrm{mL}, 113.8 \mu \mathrm{g} /$ $\mathrm{mL}, 37.9 \mu \mathrm{g} / \mathrm{mL}$ and $11.4 \mu \mathrm{g} / \mathrm{mL}$, to yield final BMP-2 concentrations in the hydrogel formulation of $50 \mu \mathrm{g} / \mathrm{mL}, 15 \mu \mathrm{g} / \mathrm{mL}, 5 \mu \mathrm{g} / \mathrm{mL}$ and $1.5 \mu \mathrm{g} / \mathrm{mL}$, respectively. Next day, when all BMP-2-containing liquid was absorbed, $1014 \mu \mathrm{L}$ of the $2 \% \mathrm{w} / \mathrm{v}$ SLG20 solution were added and the swollen microspheres were resuspended. Then, $106 \mu \mathrm{L}$ of $0.06 \mathrm{M}$ fresh GDL solution were added and mixed immediately. GDL was used to dissolve minute amounts of $\mathrm{CaCO}_{3}$, thereby crosslinking alginate and increasing the mechanical property of the formulation. The formulations were thoroughly mixed, passed through a $19 \mathrm{G}$ needle immediately after addition of all components and stored overnight at $4{ }^{\circ} \mathrm{C}$ to equilibrate. Next day, the prepared formulations were mixed again prior to use.

\section{In vitro release of BMP-2 from hydrogel formulations}

Hydrogel formulations were prepared as described above, containing either fluorescently-labelled or wild-type BMP-2. Since these experiments had the objective to study only BMP-2 release, the biological activity of these proteins was not tested. $200 \mu \mathrm{L}$ of each hydrogel were added to each well of a 24well plate, inserts with a $0.4 \mu \mathrm{m}$ pore size. $1 \mathrm{~mL}$ of DMEM supplemented with $10 \%$ FBS and $1 \% \mathrm{P} / \mathrm{S}$ per well was added to the reservoir plate. The plates were incubated at $37^{\circ} \mathrm{C}$ under constant agitation at $300 \mathrm{rpm}$. At each time point, all medium (1 mL) was collected from the reservoir plate and changed with fresh medium $(1 \mathrm{~mL})$. Positive controls were $10 \mu \mathrm{g}$, $3 \mu \mathrm{g}$ or $1 \mu \mathrm{g}$ of wild type or fluorescently-labelled BMP-2 in $1 \mathrm{~mL}$ DMEM. At every time point, $100 \mu \mathrm{L}$ of these positive controls were sampled. The collected release media and control samples were analysed using the rhBMP-2 ELISA development kit, according to manufacturer's protocol. To calculate the fraction released at each time point, the concentrations detected in the release medium of the hydrogel samples were normalised to the concentrations of the positive controls, to correct for loss by adsorbance to the tube and/or degradation of the protein.

\section{Study design and ethics}

All animal experiments were performed with prior approval of the Erasmus Medical Centre ethics committee for laboratory animal use (project number: AVD101002015114 and protocol numbers: EMC 15-114-03 and EMC 15-114-04). 10-week-old male Sprague Dawley (SD) rats (Charles River) were used. The animals were randomly assigned and housed in pairs in specific-pathogen-free conditions and allowed to adapt to the conditions of the animal house for $7 \mathrm{~d}$ before implantation. The animals were maintained at $22 \pm 5^{\circ} \mathrm{C}$ on a $12 \mathrm{~h}$ dark/light cycle with access to standard rat chow and water ad libitum. 10 weeks after implantation, animals were euthanised 
with $\mathrm{CO}_{2}$ and the specimens were harvested for $\mu \mathrm{CT}$ analysis and histology.

\section{Subcutaneous injection of in situ gelling formulations to study ectopic bone formation}

To evaluate the effect of different doses of BMP-2 on ectopic bone formation, the hydrogel compositions were subcutaneously injected (total volume: $200 \mu \mathrm{L}$ per injection) into the dorsum of the rats (20 rats in total). Each animal received 4 or 5 randomly assigned injections. All injections were performed on animals under isoflurane inhalation. To study the BMP-2-dose effect on bone formation, 4 different BMP-2 concentrations were used $(50,15,5$ and $1.5 \mu \mathrm{g} / \mathrm{mL}$ ), resulting in total doses of $10 \mu \mathrm{g}, 3 \mu \mathrm{g}$, $1 \mu \mathrm{g}$ and $0.3 \mu \mathrm{g}$ BMP-2 per implant $(n=8$ per group), respectively. As a control, alginate with microspheres, but without BMP-2 was injected $(n=6)$. To investigate the spatio-temporal distribution of BMP-2 in the implanted material in vivo, $200 \mu \mathrm{L}$ of hydrogel containing fluorescently-labelled BMP-2 were injected at different doses: $10 \mu \mathrm{g}, 3 \mu \mathrm{g}$ and $1 \mu \mathrm{g}$ $(n=6)$. Longitudinal imaging was performed by $\mu \mathrm{CT}$ and in vivo imaging instruments (IVIS) biweekly until the end of the experiment (10 weeks).

\section{Calvarial defect model to study bone regeneration with in situ gelling formulations}

To evaluate the effect of two hydrogel formulations with a selected dose of BMP-2 on orthotopic bone formation, two defects of $5 \mathrm{~mm}$ in diameter were created in the rat calvaria (18 rats in total). Prior to the surgery, animals received intraperitoneal injections of $0.05 \mathrm{mg} / \mathrm{kg}$ buprenorphine (Temgesic ${ }^{\circledR}$; Indivior, Slough, UK) and $5 \mathrm{~mL} / \mathrm{kg}$ sterile normal saline to account for fluid loss. Surgeries were performed under $2.5 \%$ isoflurane anaesthesia. The animal skulls were shaved and disinfected with ethanol swabs. Then, an incision was made through the skin of the calvarium and the periosteum and full-thickness flaps were reflected. The defect was irrigated along the sagittal midline of the skull with $0.1 \mathrm{~mL}$ of $1 \%$ xylocaine with 1 : 200,000 epinephrine (AstraZeneca). Under copious sterile saline irrigation, two $5 \mathrm{~mm}$ in diameter bone defects were drilled in each animal using a micro trephine drill (Fine Science Tools, Heidelberg, Germany) and any visible debris or bone chips were removed. Then, $40 \mu \mathrm{L}$ of hydrogel formulation with BMP-2 or, as a control, without BMP-2 were injected into the defect. As sham control, empty defects were used (5 rats, 10 defects). As a biomaterial control, alginate with microspheres were injected into the defects (5 rats, 10 defects). Alginate with microspheres loaded with $50 \mu \mathrm{g} / \mathrm{mL}$ BMP-2 (3 rats, 3 defects) was used to study healing with a high BMP-2 dose; alginate with microspheres loaded with $5 \mu \mathrm{g} / \mathrm{mL}$ ( 5 rats, 10 defects) was used to study healing with a low BMP-2 dose. The animal number of the $50 \mu \mathrm{g} / \mathrm{mL}$ BMP-2 cohort was kept small because it was expected to induce bone formation, based on the results of a previous ectopic bone formation study
(Fahmy-Garcia et al., manuscript under revision). After implantation, the periosteum and the skin above the defects were repositioned and sutured with polylactic acid sutures (Vycril 4.0, Ethicon, Johnson \& Johnson, São José dos Campos, Brazil). During the next $3 \mathrm{~d}$, all animals received three postoperative doses of buprenorphine for analgesia every $10 \mathrm{~h}$. Longitudinal imaging was performed biweekly by $\mu \mathrm{CT}$ until week 10. 10 weeks after implantation, animals were euthanised with $\mathrm{CO}_{2}$ and the specimens were harvested for $\mu \mathrm{CT}$ analysis and histology.

\section{$\mu C T$ imaging}

$\mu \mathrm{CT}$ (Quantum FX, PerkinElmer) was used to image animals 1, 2, 4, 6, 8 and 10 weeks after injection and the implants retrieved at week 10 . To image the ectopic bone in vivo, the following parameters were used: field of view, $73 \mathrm{~mm}$; voltage, $90 \mathrm{kV}$; current, $160 \mu \mathrm{A}$; scan time, $120 \mathrm{~s}$; resolution, $148 \mu \mathrm{m}$. To image the retrieved ectopic bone field of view of $20 \mathrm{~mm}$, scan time of $120 \mathrm{~s}$ and resolution of $40 \mu \mathrm{m}$ were used. To image the calvarial defects, a $30 \mathrm{~mm}$ field of view, scan time of $3 \mathrm{~min}$ and resolution of $59 \mu \mathrm{m}$ were used. The trabecular and cortical bone mineral density (BMD) were determined based on the calibration scanning, using two phantoms with known density $\left(0.25 \mathrm{~g} / \mathrm{cm}^{3}\right.$ and $0.75 \mathrm{~g} / \mathrm{cm}^{3}$; Bruker MicroCT) measured under identical conditions. For image processing, Analyze software version 11.0 was used (Mayoclinic, Rochester, MN, USA). Threshold levels were set to $0.11 \mathrm{~g} / \mathrm{cm}^{3}, 400$ Hounsfield units.

\section{Fluorescence imaging in vivo}

An IVIS Imaging System 200 (PerkinElmer) was used to image fluorescent $\mathrm{BMP}$ in the animals immediately after the injection, $3 \mathrm{~d}$ and 1, 2, 4, 6, 8 and 10 weeks after injection. The following imaging parameters were used: exposure time, $20 \mathrm{~s}$; excitation, $745 \mathrm{~nm}$; emission, $820 \mathrm{~nm}$ and $840 \mathrm{~nm}$. For the image analysis, the region of interest for each implant was selected as a circle with an area of $3.0 \pm 0.1 \mathrm{~cm}^{2}$ and the total radiant efficiency $\left[(\mathrm{p} / \mathrm{s}) /\left(\mu \mathrm{W} / \mathrm{cm}^{2}\right)\right]$ was calculated by the Living Image ${ }^{\circledR}$ software (PerkinElmer). A region of interest of $3 \mathrm{~cm}^{2}$ was selected since this was the magnitude of the area where the signal was detected directly after injection.

\section{Histology}

For histological analysis of the subcutaneous ectopic bone formation, specimens were fixed in $4 \%$ formalin solution for $48 \mathrm{~h}$ and decalcified with $10 \%$ ethylenediaminetetraacetic acid (EDTA) for 2-4 weeks. Implants were dehydrated in graded ethanol solution from $70 \%$ to $100 \%$ and embedded in paraffin. $6 \mu \mathrm{m}$-thick sections were prepared using a Leica microtome and mounted on subbed glass slides (ThermoFisher Scientific). Three cross sections, at least $200 \mu \mathrm{m}$ apart from each other, were collected from each implant. The sections were deparaffinised and rinsed with distilled water to be stained with haematoxylin and eosin (H\&E). For calvaria samples, 
10 weeks after implantation, the relevant part of the skull was removed and fixed in neutral buffered $4 \%$ formalin solution for $3 \mathrm{~d}$, dehydrated in graded ethanol solution from $70 \%$ to $100 \%$ and embedded in methyl methacrylate resin. $10 \mu \mathrm{m}$-thick sections were generated along the long axis of the cylindrical samples on a saw microtome system (Leica 4 SP1600). Samples were stained with von Kossa and Goldner's trichrome stainings, as previously described (Gruber, 1992; van der Eerden et al., 2013). The sections were imaged by NanoZoomer-XR (Hamamatsu, Japan).

\section{Statistical analysis}

The quantitative $\mu \mathrm{CT}$ data of retrieved ectopic bone were analysed using one-way analysis of variance (ANOVA) and a Bonferroni post-hoc multiple comparison test. In vivo calvaria $\mu \mathrm{CT}$ data were analysed using two-way analysis of variance (ANOVA) and a Bonferroni post-hoc multiple comparison test. A value of $p<0.05$ was considered statistically significant. Linear regression analysis of $\mu \mathrm{CT}$ data was performed by GraphPad, to analyse the time-dependent bone formation.

\section{Results}

BMP-2 was retained for at least 4 weeks in vivo To monitor the retention of BMP-2 in vivo, composite hydrogels (alginate with RCP microspheres), with three different doses of fluorescently-labelled BMP2 , were used. First, it was confirmed in vitro that the release of fluorescently-tagged (fluo) BMP-2 from the hydrogels was similar to wild type BMP-2 (Fig. 1). The difference between the release of the two proteins was less than $10 \%$, showing that labelled protein could be used to study retention of BMP-2 in vivo. Then, the fluorescence signal (shown as radiance efficiency) of the 3 doses injected subcutaneously was followed in vivo by fluorescence imaging. The fluorescence signal generated by the three different BMP-2 doses decreased until week 4 (Fig. 2). After 4 weeks, all fluorescence curves levelled off. Interestingly, the fluorescence values did not drop to the background value, indicating the presence of some remaining BMP-2 in the hydrogels. The curves corresponding to the different doses were not significantly different due to high variation among the animals (Fig. 2).

\section{Microspheres with alginate hydrogel induced BMP-2 dose-dependent ectopic bone formation}

The effect of the BMP-2 dose on subcutaneous ectopic bone formation was investigated over a period of 10 weeks using 4 different BMP-2 doses (representative $\mu \mathrm{CT}$ images are shown in Fig. 3a). At the 10-week endpoint, the bone volume formation resulted to be dose-dependent (Fig. 3b). The highest dose of $10 \mu \mathrm{g}(50 \mu \mathrm{g} / \mathrm{mL})$ induced the largest volume of ectopic bone formation, while the lowest doses of $0.3 \mu \mathrm{g}(1.5 \mu \mathrm{g} / \mathrm{mL})$ and $0 \mu \mathrm{g}$ of BMP-2 failed to form bone. The composite hydrogel containing $1 \mu \mathrm{g}$ of BMP-2 $(5 \mu \mathrm{g} / \mathrm{mL})$ formed just a minute bone volume, indicating that this dose was the threshold of ectopic bone induction in rats for this composite hydrogel. The bone mineral density of the formed bone did not differ significantly (Fig. 3c): $0.5 \mathrm{~g} / \mathrm{cm}^{3}$ for $3 \mu \mathrm{g}$ and $10 \mu \mathrm{g}$ of BMP-2 and $0.35 \mathrm{~g} / \mathrm{cm}^{3}$ for $1 \mu \mathrm{g}$ of BMP-2. For comparison, tibiae were extracted and imaged using the same instrumental settings. The cortical and trabecular bone of the tibiae had a density between $1.2-2.0 \mathrm{~g} / \mathrm{cm}^{3}$ and $0.15-0.5 \mathrm{~g} / \mathrm{cm}^{3}$, respectively, showing that ectopic bone formed subcutaneously had a density in the range of trabecular bone.

\section{Microspheres with alginate hydrogel containing different doses of BMP-2 showed different kinetics of bone formation}

Longitudinal $\mu \mathrm{CT}$ imaging of rats for 10 weeks revealed a dose-dependent rate of ectopic bone formation (Fig. 4a,b). The volume of ectopic bone in the $10 \mu \mathrm{g}$ of BMP-2 group increased linearly between week 1 and week 8 , with a rate of $16.9 \pm 0.8 \mathrm{~mm}^{3}$ / week $\left(r^{2}=0.99\right)$, after which a plateau was reached. A 10-week endpoint was decided upon, based on the longitudinal $\mu \mathrm{CT}$ imaging. Ectopic bone volume did not increase between 8 and 10 weeks for the highest dose; therefore, the experiment was ended at 10 weeks. In the $3 \mu \mathrm{g}$ of BMP-2 group, a two-phase linear trend was observed. Between 2 and 6 weeks, a linear increase in bone volume, with a rate of $10.2 \pm 0.5 \mathrm{~mm}^{3} /$ week $\left(r^{2}=0.99\right)$, was observed, while a slower linear trend was detected between 6 and 10 weeks, with a
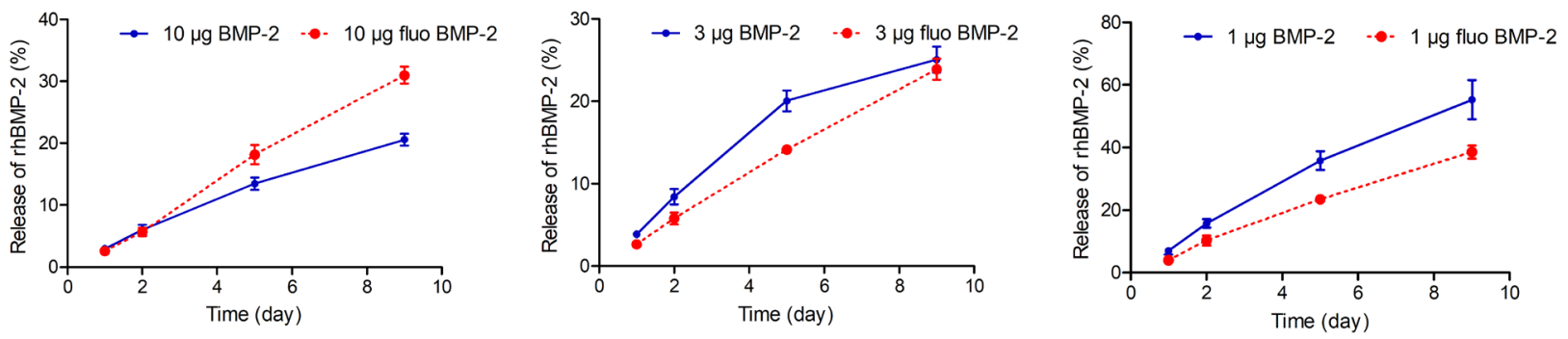

Fig. 1. In vitro release of fluorescently-labelled and non-labelled BMP-2 from the RCP microspheres with alginate hydrogel, showing no major difference between labelled and non-labelled BMP-2 release in vitro in DMEM with $10 \%$ FBS and $1 \% \mathrm{P} / \mathrm{S}$. 
rate of $3.4 \pm 0.4 \mathrm{~mm}^{3} /$ week $\left(\mathrm{r}^{2}=0.99\right)$. Although the amount of ectopic bone formed by $1 \mu \mathrm{g}$ of BMP-2 was very small, with a volume of only $3.0 \pm 5.5 \mathrm{~mm}^{3}$ (mean \pm SD) at week 10 , the bone volume linearly increased between 1 week and 10 weeks (rate $=0.36 \pm 0.1 \mathrm{~mm}^{3}$ ) week, $\left.r^{2}=0.96\right)$.
Significant mineralisation could be observed after 2 weeks (Fig. 4c). A linear increase in bone density was seen with $10 \mu \mathrm{g}$ of BMP-2 between 2 and 10 weeks, with a rate of $0.025 \pm 0.002 \mathrm{~g} / \mathrm{cm}^{3}$ per week $\left(r^{2}=0.98\right)$. In contrast to the bone volume, the mineral density did not reach a plateau at 10 weeks, a

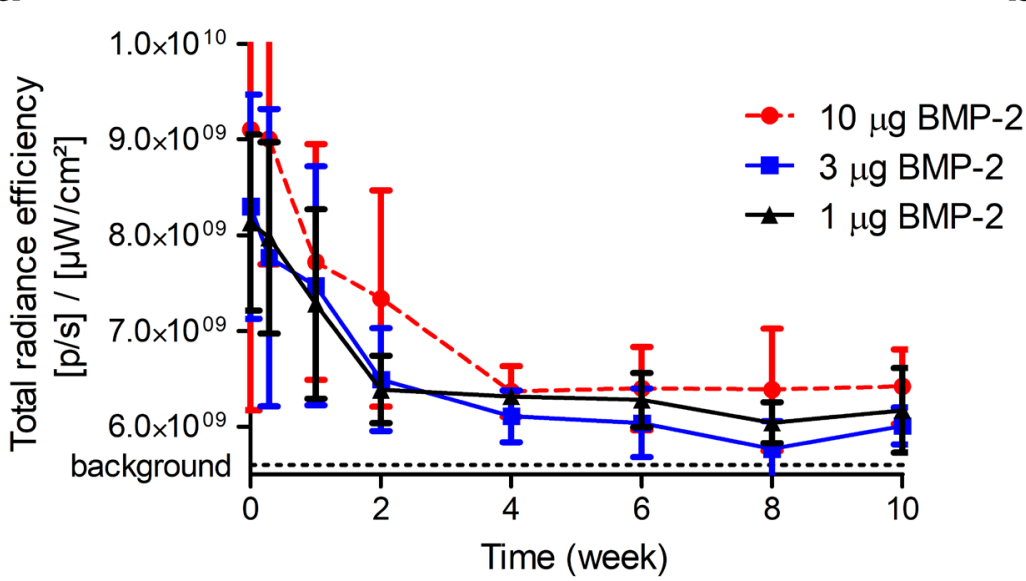

b

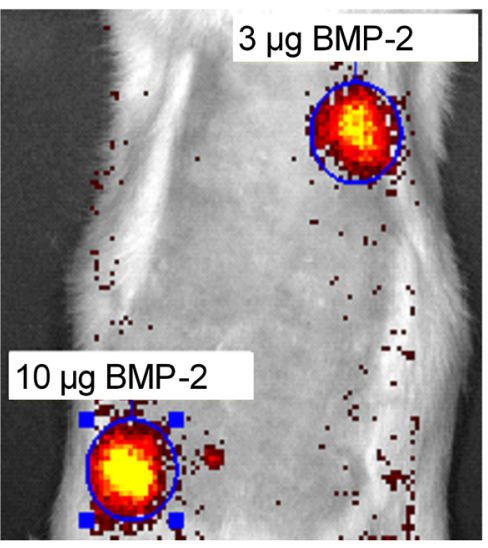

Fig. 2. (a) BMP-2 was retained in the RCP microspheres with alginate hydrogels in vivo for at least 4 weeks. The total radiance efficiency of the fluorescence signal was shown for three different doses of fluorescent BMP-2- $(10 \mu \mathrm{g}, 3 \mu \mathrm{g}$ and $1 \mu \mathrm{g})$ containing RCP microspheres with alginate that were injected subcutaneously in SD rats ( $n=6$ injections). (b) Representative image of in vivo fluorescence imaging.

a

\section{$0 \mu g$ per implant}
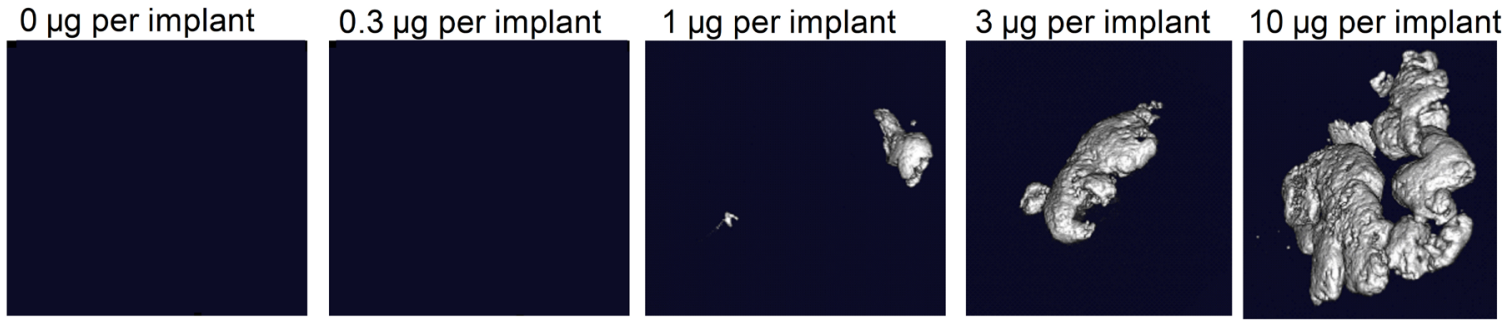

b

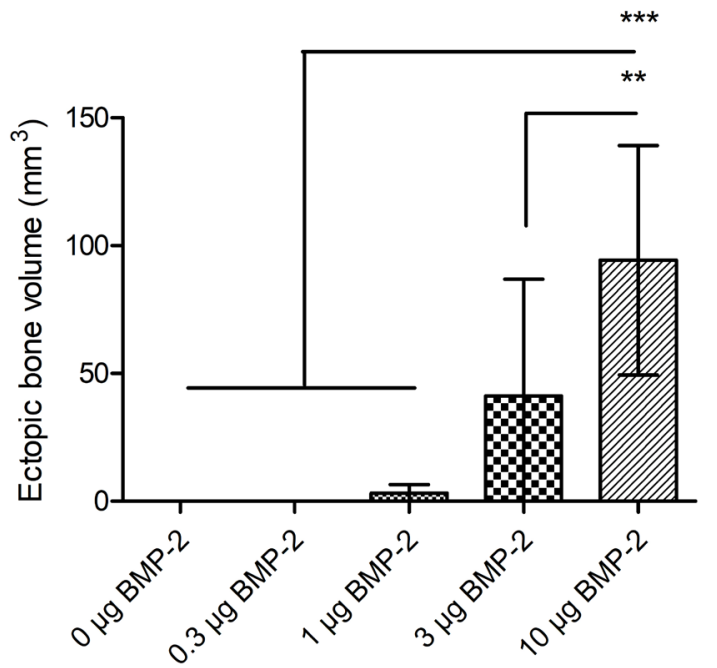

C

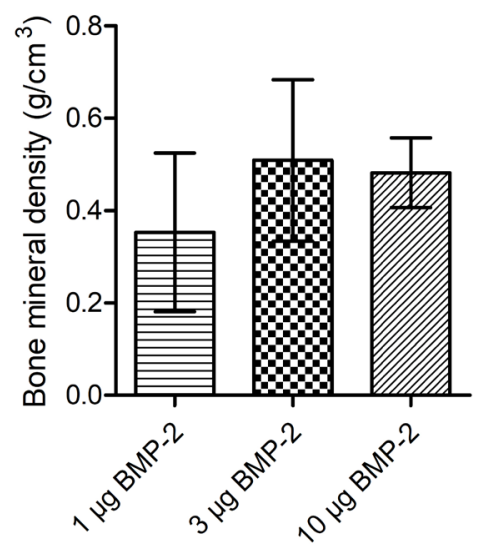

Fig. 3. Ectopic bone formation at 10 weeks was BMP-2 dose-dependent. (a) Representative images of $\mu \mathrm{CT}$ of implants retrieved at 10 weeks. (b) Volume of ectopic bone in $\mathrm{mm}^{3}$. (c) Bone mineral density after thresholding to $0.11 \mathrm{~g} / \mathrm{cm}^{3}, 400$ Hounsfield units. (a,b,c) Five different doses of BMP-2- $(10 \mu \mathrm{g}, 3 \mu \mathrm{g}, 1 \mu \mathrm{g}$, $0.3 \mu \mathrm{g}$ and $0 \mu \mathrm{g})$ containing RCP microspheres with alginate $(200 \mu \mathrm{L})$ were injected subcutaneously in $\mathrm{SD}$ rats $(n=8$ injections). Data are shown as mean $\pm \mathrm{SD}$, one-way ANOVA was performed to compare treatment groups. ${ }^{* *} p<0.05,{ }^{* * *} p<0.001$. 
suggesting that mineralisation could continue for longer than 10 weeks. Similarly, $3 \mu \mathrm{g}$ of BMP-2 showed a linear increase in bone density between 2 and 10 weeks, with a rate of $0.019 \pm 0.002 \mathrm{~g} / \mathrm{cm}^{3}$ $\left(\mathrm{r}^{2}=0.96\right)$. The $1 \mu \mathrm{g}$-BMP-2-comprising hydrogel clearly mineralised slower than the other two doses, with a rate of only $0.005 \pm 0.001 \mathrm{~g} / \mathrm{cm}^{3}\left(\mathrm{r}^{2}=0.97\right)$.

\section{Ectopic bone formation was confirmed by histology}

The morphology of ectopic bone induced by five different doses of BMP-2- $(10 \mu \mathrm{g}, 3 \mu \mathrm{g}, 1 \mu \mathrm{g}, 0.3 \mu \mathrm{g}$ and $0 \mu \mathrm{g}$ ) containing hydrogel was evaluated by histology at week 10. Bone tissue could be identified for the $10 \mu \mathrm{g}, 3 \mu \mathrm{g}$ and $1 \mu \mathrm{g}$ of BMP-2-comprising hydrogels and no bone was found for the two lowest doses of $0.3 \mu \mathrm{g}$ and $0 \mu \mathrm{g}$. The largest area of ectopic bone was found in the $10 \mu \mathrm{g}$ samples (Fig. 5), thereby confirming the $\mu \mathrm{CT}$ data (Fig. 3). Interestingly, for all BMP-2 doses, remnants of microspheres and gels could be observed, indicating that the implants were not yet fully degraded after 10 weeks. This result was in line with the long-term retention of BMP-2, as observed by fluorescence imaging. Bone formation was not only observed at the periphery of the hydrogel, but also in some samples within the hydrogel construct. Microspheres were also observed within the hydrogel construct. Some of the microspheres were intact, some were infiltrated with cells. The infiltrated microspheres changed the spherical morphology, probably as a sign of degradation. Small ossicles were detected around some microspheres. Also, around the implants, a layer of fibrous tissue was observed, which is a typical foreign body response upon implantation (Morais et al., 2010).

\section{Microspheres with alginate hydrogel containing $50 \mu \mathrm{g} / \mathrm{mL}$ BMP-2 induced bone formation in a rat calvarial defect model}

The regeneration capacity of the composite hydrogels loaded with BMP-2 was tested in a subcritical-sized calvarial defect model. Biomaterial only, $5 \mu \mathrm{g} /$ $\mathrm{mL}$ or $50 \mu \mathrm{g} / \mathrm{mL}$ BMP-2-loaded biomaterials were injected into a $5 \mathrm{~mm}$ calvarial defect and empty defect (sham) was used as a control (Fig. 6a). The bone volume with $50 \mu \mathrm{g} / \mathrm{mL}$ BMP-2 was significantly larger than in all other groups (Fig. 6b), showing the regenerative capacity of this concentration of BMP-2 in the composite hydrogel formulation. The low concentration $(5 \mu \mathrm{g} / \mathrm{mL})$ did not form any additional bone as compared to the biomaterial only or empty defect (sham) control. Interestingly, the bone volume of the empty defect was slightly higher at week 2 as compared to the biomaterial only, albeit the difference was not statistically significant. At the end of the experiment, biomaterial and empty defect groups produced similar bone volumes. The bone mineral density gradually increased over time (Fig. 6c). At week 2, $50 \mu \mathrm{g} / \mathrm{mL} \mathrm{BMP-2} \mathrm{had} \mathrm{a} \mathrm{lower}$ density when compared to $5 \mu \mathrm{g} / \mathrm{mL}$ BMP-2. This effect reversed later at week 8 and 10, when $50 \mu \mathrm{g} /$ $\mathrm{mL}$ BMP-2 induced higher density as compared to $5 \mu \mathrm{g} / \mathrm{mL}-\mathrm{BMP}-2$-treated group. von Kossa staining and Goldner's trichrome staining on the calvaria confirmed the regeneration of the bone defect a

\section{$10 \mu \mathrm{g}$}
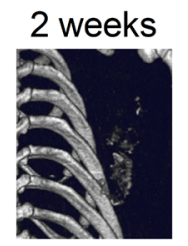

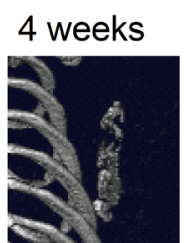

6 weeks

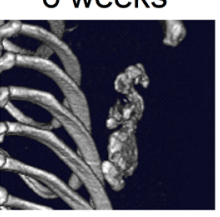

8 weeks

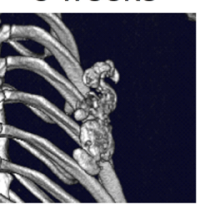

10 weeks

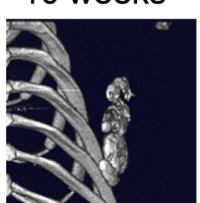

b

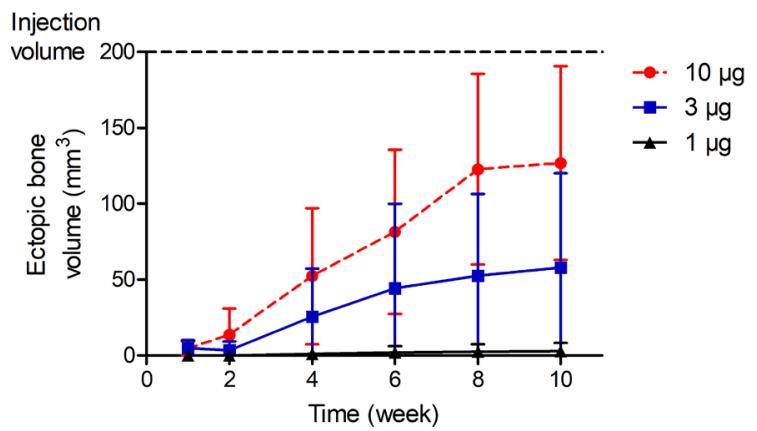

C

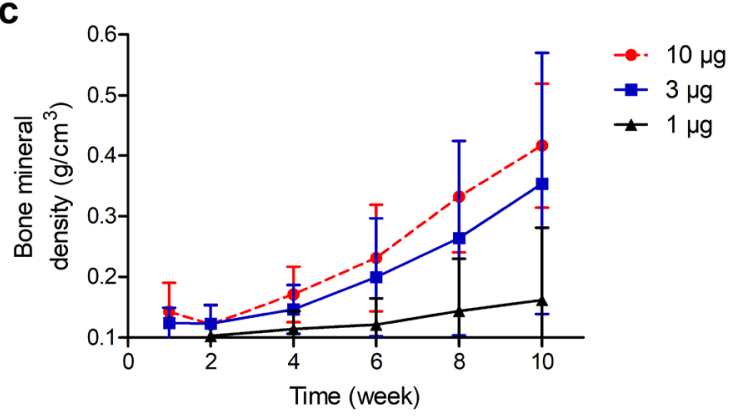

Fig. 4. Ectopic bone volume and density increase over the time course of 10 weeks was BMP-2 dosedependent. (a) Representative $\mu \mathrm{CT}$ images of bone formed by $10 \mu \mathrm{g}$ of BMP-2 administration over 10 weeks. (b) Volume of ectopic bone in $\mathrm{mm}^{3}$ after thresholding. (c) Mineral density of bone in $\mathrm{g} / \mathrm{cm}^{3}$ after thresholding. Threshold was set to $0.035 \mathrm{~g} / \mathrm{cm}^{3}$ to discriminate mineralised tissue from soft tissue. (a,b,c) Five different doses of BMP-2- $(10 \mu \mathrm{g}, 3 \mu \mathrm{g}, 1 \mu \mathrm{g}, 0.3 \mu \mathrm{g}$ and $0 \mu \mathrm{g})$ containing RCP microspheres with alginate were injected subcutaneously in SD rats $(n=8$ injections). Data are shown as mean \pm SD. Since $0.3 \mu \mathrm{g}$ and $0 \mu \mathrm{g}$ BMP-2 did not form any bone, they are not represented in this figure. 
(Fig. 7). Empty defect, biomaterial control or low concentration $(5 \mu \mathrm{g} / \mathrm{mL})$ did not bridge the bone defect at week 10 . The $50 \mu \mathrm{g} / \mathrm{mL}$ BMP-2 concentration was effective in bridging the $5 \mathrm{~mm}$ calvarial defect.

\section{Discussion}

This study aimed at investigating the use of a slow release system to lower the effective BMP-2 dose, the effect on ectopic bone formation of the BMP-2 dose delivered by an in situ gelling hydrogel formulation and the bone repair capacity of two selected doses of BMP-2. The composite hydrogel provided sustained release of BMP-2 for 4 weeks, as shown in vivo by fluorescence imaging. Ectopic bone was formed for three different doses of BMP-2 (50, 15 and $5 \mu \mathrm{g} / \mathrm{mL}$ in a $200 \mu \mathrm{L}$ implant) in a dose- and time-dependent manner, with the highest BMP-2 dose showing the fastest bone growth and highest bone volume at 10 weeks. The bone-forming dose of $50 \mu \mathrm{g} / \mathrm{mL}(2 \mu \mathrm{g}$ per implant in a $5 \mathrm{~mm}$ defect) was confirmed to be also effective in a subcritical calvarial bone defect model.

The BMP-2 delivery system used was selected based on a previous study where a hydrogel composed of SLG alginate and BMP-2-loaded RCP-microspheres provide superior ectopic bone formation as compared to other hydrogel formulations (Fahmy-Garcia et al., manuscript under revision). The advantages of this delivery system are the easy handling (due to its thixotropic behaviour), the sustained BMP-2 release profile and the presence of cell attachment sites (due to the RCP microspheres). Differently from other injectable hydrogel systems, e.g. the hydrogel developed by Seo et al. (2017), the used system contains RCP microspheres that have excellent cell attachment properties (Parvizi et al., 2016) and a specific binding affinity to BMP-2

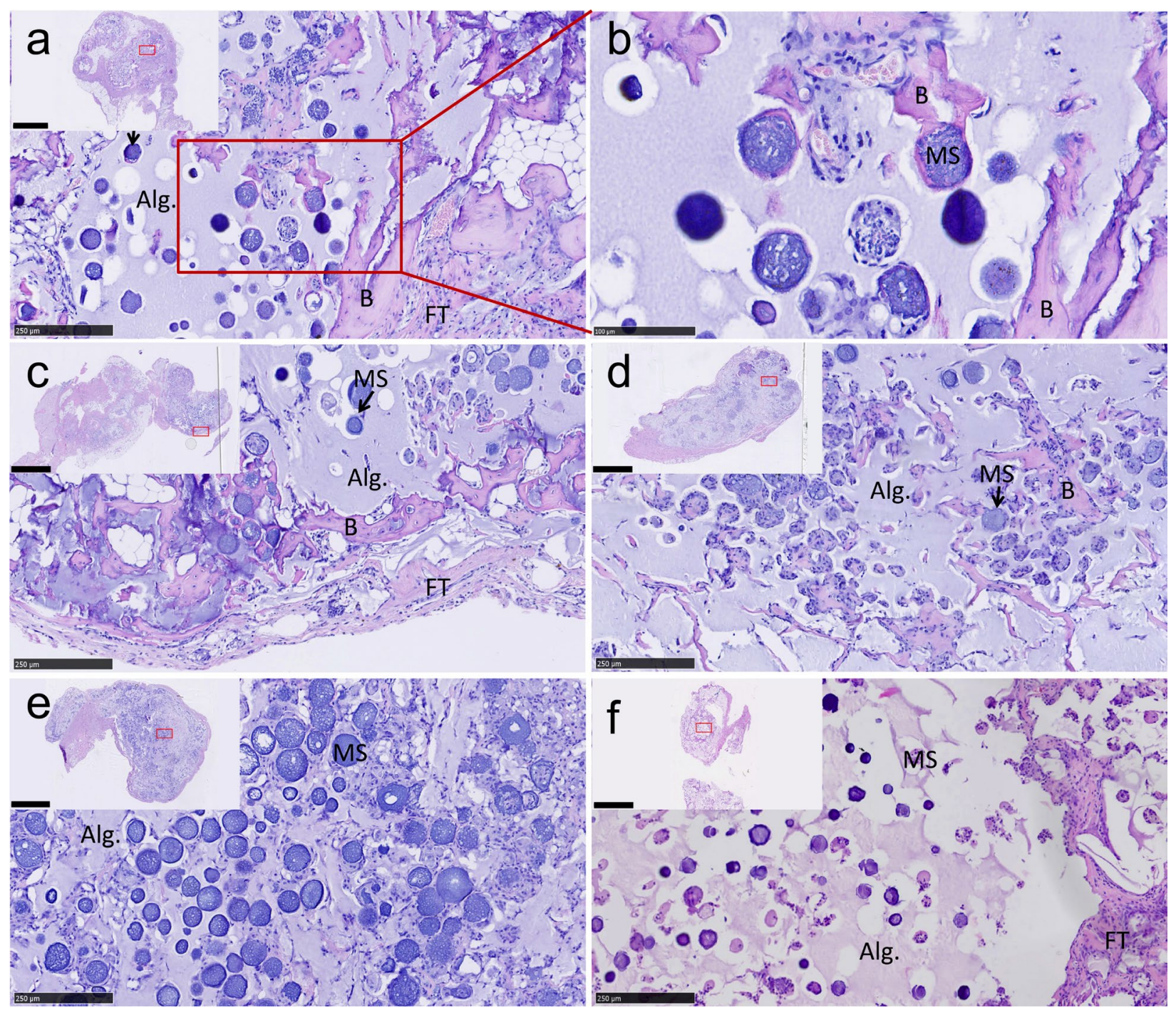

Fig. 5. Bone formation was confirmed by histology. H\&E staining for (a) $10 \mu \mathrm{g}$, (c) $3 \mu \mathrm{g}$, (d) $1 \mu$, while no bone was observed for (e) $0.3 \mu \mathrm{g}$ and (f) $0 \mu \mathrm{g}$ of BMP-2-containing RCP microsphere with alginate gels. (b) A closer representation of the $10 \mu \mathrm{g}$ of BMP-2 sample showing bony tissue around microspheres. RCP microspheres (MS), alginate hydrogel (Alg.), bone formation (B) and fibrous tissue (FT) are indicated. Scale bar is $250 \mu \mathrm{m}$ for $\mathbf{a}, \mathbf{c}, \mathbf{d}, \mathbf{e}, \mathbf{f}$ and $100 \mu \mathrm{m}$ for $\mathbf{b}$. Scale bars of the insert images are $2.5 \mathrm{~mm}$ and red boxes indicate the area of high magnification. 

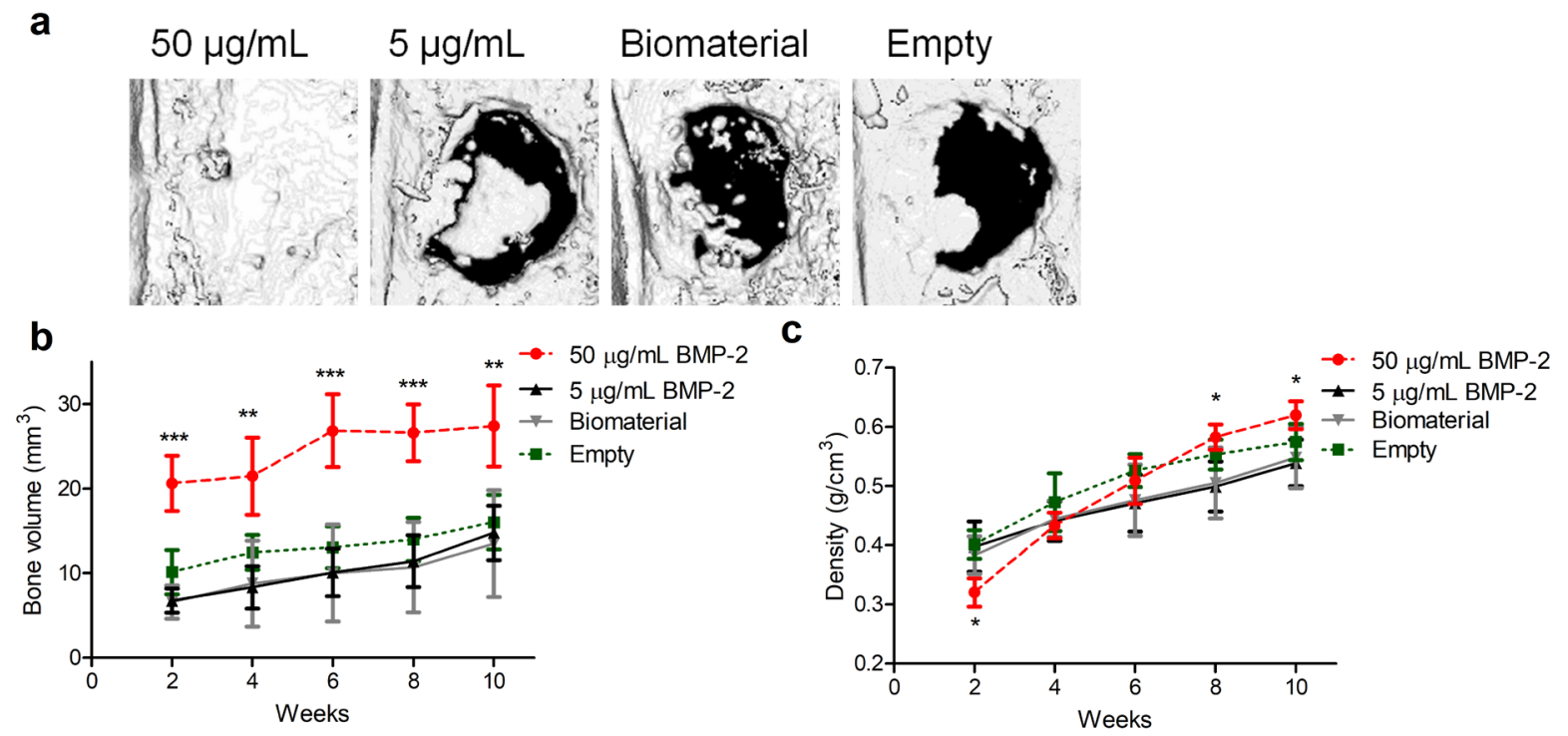

Fig. 6. (a). Representative $\mu \mathrm{CT}$ images of calvaria (superior view) at week 10 after surgery and implantation. (b). Bone volume showing the regeneration of calvarial defects over 10 weeks. The bone volume of $50 \mu \mathrm{g} / \mathrm{mL}$ BMP-2-containing biomaterial was significantly higher at all time points as compared to $5 \mu \mathrm{g} /$ mL BMP-2, biomaterial and empty defect groups $\left({ }^{* *} p<0.01\right.$ or $\left.{ }^{* * *} p<0.001\right)$. (c) Bone density showing the regeneration of calvaria over 10 weeks. Bone density induced by $50 \mu \mathrm{g} / \mathrm{mL}$ BMP-2 was lower than that of $5 \mu \mathrm{g} / \mathrm{mL}$ BMP-2 group at week $2\left({ }^{*} p<0.05\right)$. At week 8 and 10 , density of induced bone tissue was higher in $50 \mu \mathrm{g} / \mathrm{mL}$ BMP-2 than $5 \mu \mathrm{g} / \mathrm{mL}$ BMP-2 group $\left({ }^{*} p<0.05\right)$. Treatment groups were empty control $(n=10)$, biomaterial only $(n=10), 5 \mu \mathrm{g} / \mathrm{mL}$ BMP-2-containing biomaterial $(n=10)$ and $50 \mu \mathrm{g} / \mathrm{mL}$ BMP-2-containing biomaterial $(n=3)$. Data are shown as mean \pm SD, two-way ANOVA was performed to compare treatment groups.

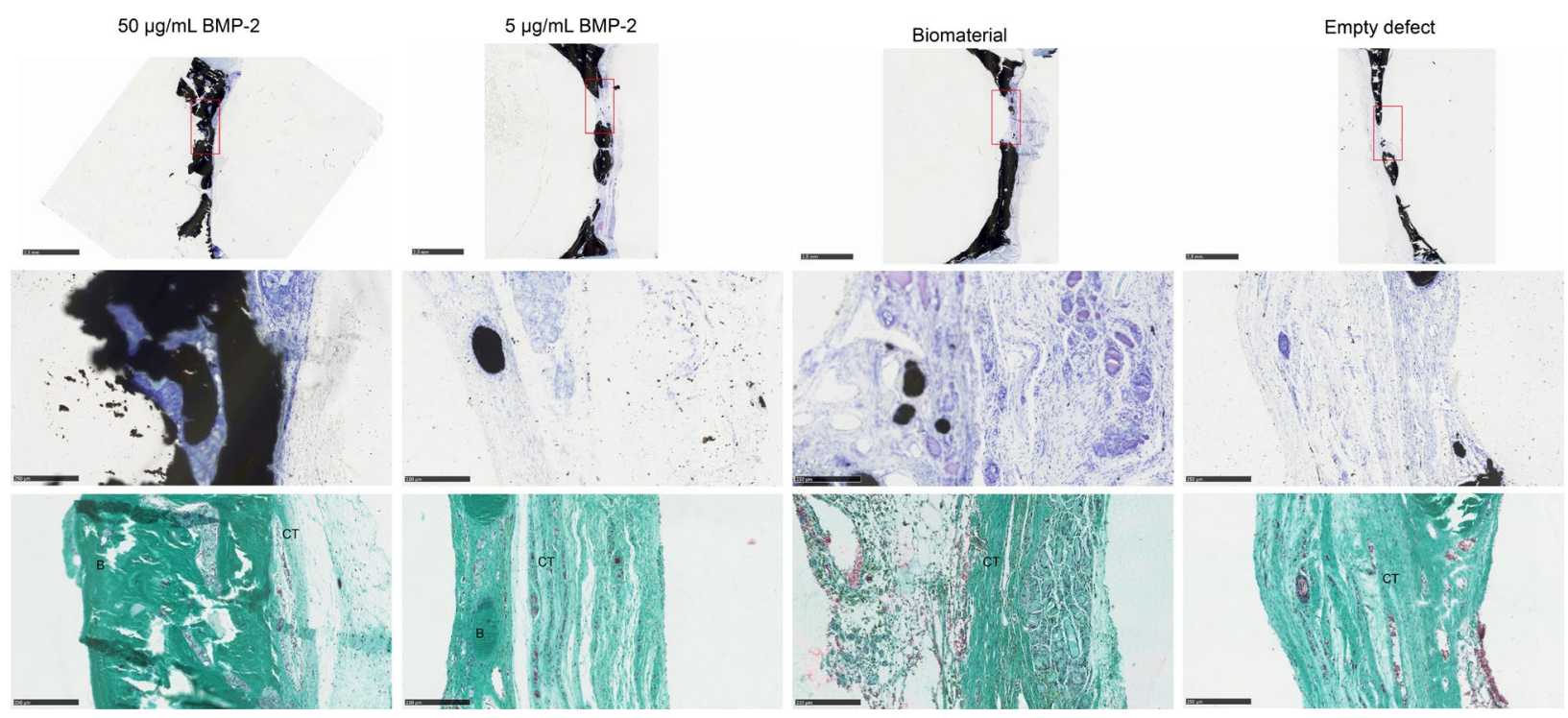

Fig. 7. The first two rows show von Kossa staining, the lower row Goldner's trichrome staining of the calvarial defect samples. From left to right: $50 \mu \mathrm{g} / \mathrm{mL}$ BMP-2, $5 \mu \mathrm{g} / \mathrm{mL}$ BMP-2, biomaterial control and empty defect. Bone healing and bridging of the defect was confirmed for the $50 \mu \mathrm{g} / \mathrm{mL}$ BMP-2 group. Red boxes indicate the area of the defect. Scale bars of the first row are $2.5 \mathrm{~mm}$, second and third row are $250 \mu \mathrm{m}$. B: bone; CT: connective tissue. 
(Mumcuoglu et al., 2018). In the current study, it was shown that in situ gelling hydrogel composite with a concentration of $50 \mathrm{ug} / \mathrm{mL}$ BMP-2 (2 $\mu \mathrm{g}$ per implant in a $5 \mathrm{~mm}$ defect) successfully regenerated bone. In other preclinical studies with BMP-2 carriers, the BMP-2 dose needed to heal a critical sized defect is generally higher; in a rat calvarial model similar to the one used in the current study, complete healing of the defects is achieved with poly lactic-co-glycolic acid (PLGA) membranes adsorbed with $5 \mathrm{mg} / \mathrm{mL}$ of BMP-2 (Ono et al., 2013). Young et al. (2009), using a $8 \mathrm{~mm}$ rat calvarial model and $0.5 \mu \mathrm{g}$ and $1 \mu \mathrm{g}$ of BMP-2 per implant delivered with gelatin particles, show an incomplete bone bridging. Partial healing of $8 \mathrm{~mm}$ rat calvarial defects of approximately $20 \%$ and $60 \%$ is observed with a composite comprising segmented polyurethane, poly[lactic-co-glycolic acid] and $\beta$-tricalcium phosphate loaded with $1.6 \mu \mathrm{g}$ and $6.5 \mu \mathrm{g}$ of rhBMP-2, respectively (Rodriguez-Evora et al., 2013). Besides, other BMP-2 carriers induce lower ectopic bone volumes. For example, silk fibroin $\left(2 \mathrm{~mm}^{3}\right)$ (Bessa et al., 2010) and collagen sponge $\left(5 \mathrm{~mm}^{3}\right)$ (Kim et al., 2011) form a max of $5 \mathrm{~mm}^{3}$ of ectopic bone using $5 \mu \mathrm{g}$ of BMP-2, which is lower than the $41 \mathrm{~mm}^{3}$ induced with $3 \mu \mathrm{g}(15 \mu \mathrm{g} / \mathrm{mL})$ of BMP-2, as done in the current ectopic model. In a composite gelatin microsphere, biphasic calcium phosphate hydrogel system, $13 \mathrm{~mm}^{3}$ of ectopic bone are achieved with $100 \mu \mathrm{g} / \mathrm{mL}$ BMP-2 (Poldervaart et al., 2013). Considering these earlier studies, the current study showed that the in situ gelling formulation of the RCP microspheres with alginate is a promising BMP2 delivery system that might reduce the required effective dose of BMP-2 and, thus, potentially mitigate the adverse effects of BMP-2.

Besides the required threshold or effective dose of BMP-2, the hydrogel matrix - to which the characteristics of the biomaterial, such as release, integrity, degradation and cell infiltration, should be aligned - also affects the bone formation process. Factors such as speed of bone formation, amount and location of the formed bone are important to consider. The natural fracture healing process requires around 4 weeks in rodents (Einhorn and Gerstenfeld, 2015) and it can take up to 3-4 months in humans (Garcia et al., 2013). In the used ectopic model, the kinetics of bone formation was shown to be linear for the $10 \mu \mathrm{g}$ of BMP-2 group, between week 1 and 8 , while the main release of BMP-2 was observed in the first 4 weeks, both processes matching the time frame of natural bone healing processes (Marsell and Einhorn, 2011). Interestingly, after 4 weeks, a small portion of BMP-2 was retained inside the hydrogel, probably due to the strong interaction between BMP-2 and the RCP microspheres (Mumcuoglu et al., 2018). This portion of BMP-2 will only be released upon further degradation of the material and could probably contribute to the bone volume increase after 4 weeks. The main determinant of BMP-2 release in vivo is the specific interaction and the degradation of the particles. The RCP amino acid sequence will most probably be a main contributor to the release profile, although it is not possible to exclude that polarity and ionic strength will also affect the release profile of proteins by changing the interaction with the matrix. With $10 \mu \mathrm{g}$ of BMP-2, ectopic bone volume reached a plateau at week 8 . This suggested that bone formation could be confined to the hydrogel area. Therefore, this hydrogel formulation might eliminate the risk of excessive surrounding soft tissue calcification, which is a major concern in currently used BMP-2-based therapies (James et al., 2016).

The ectopic model results indicated that hydrogels containing $3 \mu \mathrm{g}$ and $10 \mu \mathrm{g}$ of BMP-2 were not only forming bone at the periphery of the implants, but in the entire implants. Qualitative analysis of 3D $\mu \mathrm{CT}$ images revealed that the bone formation started at different locations throughout the implant around week 2 . These results corroborated previous findings (Fahmy-Garcia et al., manuscript under revision), according to which the hydrogel allows bone-forming cells to infiltrate the gel at early time points.

Interestingly, hydrogels without or with a very low dose of BMP-2 seemed to slightly, though not significantly, impede bone formation in the calvarial defect model at the early time points when compared to the empty control. After 10 weeks, bone formation in defects filled with biomaterial, without or with a low dose of BMP-2, was not different from the empty defect control. It is possible that the empty defect induced higher initial inflammation and faster infiltration of inflammatory cells as compared to the RCP microspheres with alginate and, therefore, the healing process started earlier. The safety of the separate components of this system are verified by Novamatrix and Fujifilm. On their website (www. novamatrix.biz), toxicology studies of alginate are reported. The biocompatibility of RCP is confirmed in a previous study by Parvizi (2016). Histological analysis of the samples at week 10 showed infiltrated cells in the defect area for both defects filled with biomaterials and empty control. These cells were mainly macrophages. A hydrogel-dependent cellular response of different hydrogels in ectopic bone formation is already shown (Fahmy-Garcia et al., manuscript under revision). For the SLG alginate gel selected for this study, the number of inflammatory cells is initially high and decrease at later time points (Fahmy-Garcia et al., manuscript under revision). Alginate is known for poor cell attachment (Rowley et al., 1999; Sarker et al., 2014). Possibly, alginate slightly delays cell infiltration as compared to natural bone healing environment where there is a fibrin clot hosting the infiltrated cells. These effects could be object of a future study. However, as differences did not reach statistical significance and the endpoint healing for both groups was similar, an inhibitory effect of the hydrogel matrix on the overall bone healing is not expected. Overall, the benefit of having a slow release system outweighs this minor effect, since the BMP condition healed much better than the control. 


\section{Conclusion}

The injectable slow BMP-2 release delivery system resulted in a time- and dose- dependent bone formation in an ectopic and orthotopic model. This delivery system, composed of alginate and RCP microspheres, provided sustained release of BMP-2, favoured cell attachment and induced bone formation at a relatively low dose of BMP-2, making it promising for bone regeneration therapies.

\section{Acknowledgement}

The authors thank Vincent Paes and Charlotte Gerkes for their technical assistance during the performance of the calvarial surgeries. This work was supported by the use of imaging equipment provided by the Applied Molecular Imaging Erasmus MC facility. The research leading to these results has received funding from the People Programme (Marie Curie Actions) of the European Union's Seventh Framework Programme FP7/2007- 2013/ under REA grant agreement number 607051.

\section{References}

Agrawal V, Sinha M (2016) A review on carrier systems for bone morphogenetic protein-2. J Biomed Mater Res B Appl Biomater 105: 904-925.

Bessa PC, Balmayor ER, Hartinger J, Zanoni G, Dopler D, Meinl A, Banerjee A, Casal M, Redl H, Reis RL, van Griensven M (2010) Silk fibroin microparticles as carriers for delivery of human recombinant bone morphogenetic protein-2: in vitro and in vivo bioactivity. Tissue Eng Part C Methods 16: 937-945.

Bessa PC, Casal M, Reis RL (2008) Bone morphogenetic proteins in tissue engineering: the road from laboratory to clinic, part II (BMP delivery). J Tissue Eng Regen Med 2: 81-96.

Burkus JK, Transfeldt EE, Kitchel SH, Watkins RG, Balderston RA (2002) Clinical and radiographic outcomes of anterior lumbar interbody fusion using recombinant human bone morphogenetic protein-2. Spine (Phila Pa 1976) 27: 2396-2408.

Choi JW, Jeong WS, Yang SJ, Park EJ, Oh TS, Koh KS (2016) Appropriate and effective dosage of BMP-2 for the ideal regeneration of calvarial bone defects in beagles. Plast Reconstr Surg 138: 64e-72e.

De Boer AL, Van Urk H, Bouwstra JB, Van Asten PFTM (2012) RGD containing recombinant gelatin. Google Patents, US8198047B2.

Einhorn TA, Gerstenfeld LC (2015) Fracture healing: mechanisms and interventions. Nat Rev Rheumatol 11: 45-54.

Epstein NE (2013) Complications due to the use of BMP/INFUSE in spine surgery: the evidence continues to mount. Surg Neurol Int 4: S343-352.
S Fahmy-Garcia, D Mumcuoglu, L de Miguel, V D Dieleman, BCJ van der Eerden, D Eglin, SGJM Kluijtmans, GJVM van Osch, E Farrell (2016) Injectable hydrogels comprising collagen I based recombinant peptide microspheres loaded with BMP2 promote ectopic bone formation. NBTE 25th Annual Meeting, p 53.

Garcia P, Histing T, Holstein JH, Klein M, Laschke MW, Matthys R, Ignatius A, Wildemann B, Lienau J, Peters A, Willie B, Duda G, Claes L, Pohlemann T, Menger MD (2013) Rodent animal models of delayed bone healing and non-union formation: a comprehensive review. Eur Cell Mater 26: 1-14.

Gruber HE (1992) Adaptations of Goldner's Masson trichrome stain for the study of undecalcified plastic embedded bone. Biotech Histochem 67: 30-34.

James AW, LaChaud G, Shen J, Asatrian G, Nguyen V, Zhang X, Ting K, Soo C (2016) A Review of the clinical side effects of bone morphogenetic protein-2. Tissue Eng Part B Rev 22: 284-297.

Kim IS, Lee EN, Cho TH, Song YM, Hwang SJ, Oh JH, Park EK, Koo TY, Seo YK (2011) Promising efficacy of Escherichia coli recombinant human bone morphogenetic protein-2 in collagen sponge for ectopic and orthotopic bone formation and comparison with mammalian cell recombinant human bone morphogenetic protein-2. Tissue Eng Part A 17: 337-348.

Kirsch T, Nickel J, Sebald W (2000) Isolation of recombinant $\mathrm{BMP}$ receptor IA ectodomain and its 2:1 complex with BMP-2. FEBS Lett 468: 215-219.

Li RH, Wozney JM (2001) Delivering on the promise of bone morphogenetic proteins. Trends Biotechnol 19: 255-265.

Marsell R, Einhorn TA (2011) The biology of fracture healing. Injury 42: 551-555.

Martinez-Sanz E, Alkhraisat MH, Paradas I, Lopez Y, Maldonado E, Gonzalez-Meli B, Berenguer B, Lopez-Cabarcos E, Martinez ML, Martinez-Alvarez C (2012) Osteoinduction in the palatal submucosa by injecting BMP-2 on 2 different carriers. J Craniofac Surg 23: 594-598.

McKay WF, Peckham SM, Badura JM (2007) A comprehensive clinical review of recombinant human bone morphogenetic protein-2 (INFUSE Bone Graft). Int Orthop 31: 729-734.

Morais JM, Papadimitrakopoulos F, Burgess DJ (2010) Biomaterials/tissue interactions: possible solutions to overcome foreign body response. AAPS J 12: 188-196.

Mumcuoglu D, de Miguel L, Jekhmane S, Siverino C, Nickel J, Mueller TD, van Leeuwen JP, van Osch GJ, Kluijtmans SG (2018) Collagen I derived recombinant protein microspheres as novel delivery vehicles for bone morphogenetic protein-2. Mater Sci Eng C Mater Biol Appl 84: 271-280.

Mumcuoglu D, Siverino C, Tabisz B, Kluijtmans SG, Nickel J (2017) How to use BMP-2 for clinical applications? A review on pros and cons of existing delivery strategies. J Transl Sci 3: 1-11. 
Ono M, Sonoyama W, Nema K, Hara ES, Oida Y, Pham HT, Yamamoto K, Hirota K, Sugama K, Sebald W, Kuboki T (2013) Regeneration of calvarial defects with Escherichia coli -derived rhBMP-2 adsorbed in PLGA membrane. Cells Tissues Organs 198: 367-376.

Parvizi M (2016) Cardiovascular tissue engineering and regeneration based on adipose tissue-derived stem/stromal cells. Electronic ISBNs 978-90-367-89172, University of Groningen, pp 1-203.

Parvizi M, Plantinga JA, van Speuwel-Goossens CA, van Dongen EM, Kluijtmans SG, Harmsen MC (2016) Development of recombinant collagenpeptide-based vehicles for delivery of adiposederived stromal cells. J Biomed Mater Res A 104: 503-516.

Perri B, Cooper M, Lauryssen C, Anand N (2007) Adverse swelling associated with use of rh-BMP-2 in anterior cervical discectomy and fusion: a case study. Spine J 7: 235-239.

Poldervaart MT, Wang H, van der Stok J, Weinans H, Leeuwenburgh SC, Oner FC, Dhert WJ, Alblas J (2013) Sustained release of BMP-2 in bioprinted alginate for osteogenicity in mice and rats. PLoS One 8: e72610.

Polo-Corrales L, Latorre-Esteves M, Ramirez-Vick JE (2014) Scaffold design for bone regeneration. J Nanosci Nanotechnol 14: 15-56.

Poon B, Kha T, Tran S, Dass CR (2016) Bone morphogenetic protein-2 and bone therapy: successes and pitfalls. J Pharm Pharmacol 68: 139-147.

Rengachary SS (2002) Bone morphogenetic proteins: basic concepts. Neurosurg Focus 13: e2.

Rodriguez-Evora M, Delgado A, Reyes R, Hernandez-Daranas A, Soriano I, San Roman J, Evora C (2013) Osteogenic effect of local, long versus short term BMP-2 delivery from a novel SPU-PLGAbetaTCP concentric system in a critical size defect in rats. Eur J Pharm Sci 49: 873-884.

Rowley JA, Madlambayan G, Mooney DJ (1999) Alginate hydrogels as synthetic extracellular matrix materials. Biomaterials 20: 45-53.

Sarker B, Singh R, Silva R, Roether JA, Kaschta J, Detsch R, Schubert DW, Cicha I, Boccaccini AR (2014) Evaluation of fibroblasts adhesion and proliferation on alginate-gelatin crosslinked hydrogel. PLoS One 9: e107952.

Scott MA, Levi B, Askarinam A, Nguyen A, Rackohn T, Ting K, Soo C, James AW (2012) Brief review of models of ectopic bone formation. Stem Cells Dev 21: 655-667.

Seo BB, Koh JT, Song SC (2017) Tuning physical properties and $\mathrm{BMP}-2$ release rates of injectable hydrogel systems for an optimal bone regeneration effect. Biomaterials 122: 91-104.

Shields LB, Raque GH, Glassman SD, Campbell M, Vitaz T, Harpring J, Shields CB (2006) Adverse effects associated with high-dose recombinant human bone morphogenetic protein-2 use in anterior cervical spine fusion. Spine (Phila Pa 1976) 31: 542-547.

Tazaki J, Murata M, Akazawa T, Yamamoto M, Ito K, Arisue M, Shibata T, Tabata Y (2009) BMP-2 release and dose-response studies in hydroxyapatite and beta-tricalcium phosphate. Biomed Mater Eng 19: 141-146.

Tuin A, Kluijtmans SG, Bouwstra JB, Harmsen MC, Van Luyn MJ (2010) Recombinant gelatin microspheres: novel formulations for tissue repair?. Tissue Eng Part A 16: 1811-1821.

van der Eerden BC, Oei L, Roschger P, FratzlZelman N, Hoenderop JG, van Schoor NM, PetterssonKymmer U, Schreuders-Koedam M, Uitterlinden AG, Hofman A, Suzuki M, Klaushofer K, Ohlsson C, Lips PJ, Rivadeneira F, Bindels RJ, van Leeuwen JP (2013) TRPV4 deficiency causes sexual dimorphism in bone metabolism and osteoporotic fracture risk. Bone 57: 443-454.

Woo EJ (2012) Adverse events reported after the use of recombinant human bone morphogenetic protein 2. J Oral Maxillofac Surg 70: 765-767.

Yamaji K, Kawanami M, Matsumoto A, Odajima T, Nishitani Y, Iwasaka K, Yoshimitsu K, Yoshiyama M (2007) Effects of dose of recombinant human BMP-2 on bone formation at palatal sites in young and old rats. Dent Mater J 26: 481-486.

Young S, Patel ZS, Kretlow JD, Murphy MB, Mountziaris PM, Baggett LS, Ueda H, Tabata Y, Jansen JA, Wong M, Mikos AG (2009) Dose effect of dual delivery of vascular endothelial growth factor and bone morphogenetic protein-2 on bone regeneration in a rat critical-size defect model. Tissue Eng Part A 15: 2347-2362.

Zara JN, Siu RK, Zhang X, Shen J, Ngo R, Lee M, Li W, Chiang M, Chung J, Kwak J, Wu BM, Ting K, Soo C (2011) High doses of bone morphogenetic protein 2 induce structurally abnormal bone and inflammation in vivo. Tissue Eng Part A 17: 1389-1399.

\section{Discussion with Reviewers}

Declan Devine: The animal model utilised was a calvarial model, which is a non-loaded bone, whereas BMP-2 is marketed for use in loaded environments. What effect would loading have on the scaffold properties, breakdown and release rate of BMP-2?

Authors: Mechanical loading is a very important parameter for the regeneration of load-bearing bones (Tobias, 2015, additional reference). According to rheology data (Fahmy-Garcia et al., manuscript under revision), alginate with microspheres is a thixotropic hydrogel, showing that under shear stress (500\% strain) the gel to solution transition occurs: in other words, the gel becomes a viscous liquid. When the stress is removed, the hydrogel recovers again as a result of self-healing property. Since the mechanical properties of these hydrogels are far lower than that of bone and they show thixotropic behaviour, they are not good candidates for treatment of load-bearing bones unless used in combination with fixation techniques, such as using plates and screws, or in combination with stiffer materials. In addition, the BMP-2 release may vary under mechanical loading, 
as proposed in a non-human primate study on spinal arthrodesis, in which a BMP-2-loaded collagen sponge prevents bone induction probably due to squeezing of proteins out of the sponge (Martin et al., 1999, additional reference). Thus, additional studies would be required with this material into a load-bearing defect.

Nunzia Di Maggio: May BMP-2 be combined to other growth factors in the same hydrogel? Would you comment on which other processes would be most useful to target to maximise efficient bone regeneration?

Authors: BMP-2 can be combined with other growth factors or cytokines in the same hydrogel. There are various processes that can be targeted to maximise bone formation. Vascularisation is, for example, a very important process in bone formation. Newly formed bone should be vascularised to support the process of regeneration, calcification etc.. Vascular endothelial growth factor-A (VEGF-A) (Hu and Olsen, 2016, additional reference) or another factor that can increase vascularisation can also be used within this hydrogel. Also, combinations of BMP-2 and BMP-7 might be interesting: sequential delivery of both factors increases new bone formation (Jo et al., 2015, additional reference).

Nunzia Di Maggio: For which clinical scenarios would you envision this injectable hydrogel to be most suitable?

Authors: The applications of the hydrogels in nonload-bearing bones, such as calvarium or around the orbital cavity and in small defects in the mandibular or jaw bones in the maxillofacial surgery, are possible (Jayaram et al., 2017, additional reference). There are several specific examples that applications of tissue engineering products are suitable. For example, for maxillary reconstruction of flap after a large keratocyst, a biomaterial can be used (Mesimaki et al., 2009, additional reference). Another application can be in jaw bones with osteolytic lesions (Dominijanni et al., 2012, additional reference). The reconstruction of critical size mandibular bone defects is a challenge in oral and maxillofacial surgery. For this application, scaffolds are tested (Ren et al., 2005; Yuan et al., 2007, additional reference) and the hydrogel presented in this study could be a potential material for this application. Another potential application is sinus augmentation, which is performed before dental implant surgery in case of bone loss (Schimming and Schmelzeisen, 2004; Springer et al., 2006, additional reference).

\section{Additional References}

Dominijanni A, Cristofaro MG, Brescia A, Giudice M (2012) Platelet gel in oral and maxillofacial surgery: a single-centre experience. Blood Transfus 10: 200204.

Hu K, Olsen BR (2016) The roles of vascular endothelial growth factor in bone repair and regeneration. Bone 91: 30-38.

Jayaram M, Sumankumar N, Egammai S, Rajkumar S, Nivethitha N (2017) Hydrogels in maxillofacial prosthesis. Indian J Multidiscip Dent 7: 29-33.

Jo JY, Jeong SI, Shin YM, Kang SS, Kim SE, Jeong CM, Huh JB (2015) Sequential delivery of BMP-2 and BMP-7 for bone regeneration using a heparinized collagen membrane. Int J Oral Maxillofac Surg 44: 921-928.

Martin GJ, Jr., Boden SD, Marone MA, Marone MA, Moskovitz PA (1999) Posterolateral intertransverse process spinal arthrodesis with rhBMP-2 in a nonhuman primate: important lessons learned regarding dose, carrier, and safety. J Spinal Disord 12: $179-186$.

Mesimaki K, Lindroos B, Tornwall J, Mauno J, Lindqvist C, Kontio R, Miettinen S, Suuronen R (2009) Novel maxillary reconstruction with ectopic bone formation by GMP adipose stem cells. Int J Oral Maxillofac Surg 38: 201-209.

Ren T, Ren J, Jia X, Pan K (2005) The bone formation in vitro and mandibular defect repair using PLGA porous scaffolds. J Biomed Mater Res A 74: 562-569.

Schimming R, Schmelzeisen R (2004) Tissueengineered bone for maxillary sinus augmentation. J Oral Maxillofac Surg 62: 724-729.

Springer IN, Nocini PF, Schlegel KA, De Santis D, Park J, Warnke PH, Terheyden H, Zimmermann R, Chiarini L, Gardner K, Ferrari F, Wiltfang J (2006) Two techniques for the preparation of cell-scaffold constructs suitable for sinus augmentation: steps into clinical application. Tissue Eng 12: 2649-2656.

Tobias JH (2015) Editorial: Mechanical loading and bone. Front Endocrinol (Lausanne) 6: 184.

Yuan J, Cui L, Zhang WJ, Liu W, Cao Y (2007) Repair of canine mandibular bone defects with bone marrow stromal cells and porous beta-tricalcium phosphate. Biomaterials 28: 1005-1013.

Editor's note: The Scientific Editor responsible for this paper was Chris Evans. 